This is an Accepted Manuscript of a book review published by Taylor \& Francis in Life Writing, 16 (3). pp. 487-490. available online: https://www.tandfonline.com/doi/full/10.1080/14484528.2017.1383844

Accepted version downloaded from SOAS Research Online: http://eprints.soas.ac.uk/34752

\title{
Burying Autumn: Poetry, Friendship, and Loss
}

\section{Jessica Siu-yin Yeung}

To cite this article: Jessica Siu-yin Yeung (2017): Burying Autumn: Poetry, Friendship, and Loss, Life Writing

To link to this article: http://dx.doi.org/10.1080/14484528.2017.1383844

Published online: 03 Oct 2017.

\section{BOOK REVIEW}

Burying Autumn: Poetry, Friendship, and Loss, by Hu Ying, Cambridge, MA, United States and London, Harvard University Asia Center, 2016, 365 pp., ISBN 9780674737204

The title of this book, Burying Autumn, comes from Hu Ying's commitment to retelling the compelling story of the burial of Qiu Jin (1875-1907), a poetess, androgyne, female assassin, revolutionary, and martyr in modern China. The 'Autumn' in the title refers to the subject's last name 'Qiu', which means 'autumn.' This biography is unusual and fresh as it adopts a prosopographical (collective) approach to tone down the hagiographical convention of commemorating martyrs (6). Hu follows the footsteps of the father of Chinese historiography, Sima Qian (15-86 BC) in adopting this approach to trace both Qiu and her forgotten friends, Wu Zhiying (1867-1934) and Xu Zihua (1873-1935) back to the patriarchal, Confucian, and heterosexual axis of Chinese history. Hu does this by thematising the friendship between Qiu and her sworn sisters, $\mathrm{Wu}$, the calligrapher, and $\mathrm{Xu}$, the poetess and headmistress. Hu's biographisation of these women's lives and emphasis on their sworn sisterhood is subversive from a traditional Chinese perspective. This is because among the 'five Confucian cardinal human relations', friendship does not apply to women as women's 
friendship has no 'practical value in maintaining a nonfamilial social network' (335). Hu's prosopography challenges this patriarchal tradition by establishing a framework of New Women in modern China. This framework, however, differs from the feminist ideal of New Women in late 19th-century Britain. Although both $\mathrm{Hu}$ and the Edwardian idea of New Women derive from educated women's responses to modernity, Hu's framework emphasises how women articulated their responses through traditional Chinese poetry 'like a more elaborate form of social media' (12) and how women transformed cultural traditions and maintained deep cultural roots at the same time (14).

The friendship between Qiu, $\mathrm{Wu}$, and $\mathrm{Xu}$ embodies Hu's critique of the 'traditional teachings on feminine conduct' (154) and 'dominant gender norms' at China's crossroads of modernity (104). These women's otherwise private and obscure friendship acquires a public and national significance. The choice of Qiu as the central biographical subject transforms into a public act of mourning of both pre-modern and modern Chinese martyrs at large. Hu achieves this by juxtaposing Qiu with exemplary women and legendary heroes in Chinese culture such as the fourth-century poetess Xie Daoyun (64-65), the wronged widow Dou'e in the 13th-century play The Injustice to Dou E (181), Jing Ke, an assassin who failed to assassinate the King of Qin (259-210 BC) but nevertheless secures a place in Sima Qian's 'The Biographies of Assassins' (197), and Yue Fei, a popular Chinese hero known for his loyalty to the Southern Song court (1127-1279) but put to death in the 12th century (3). The juxtaposition of Qiu with these mythological and archetypal personages seems to place Qiu in the Chinese hagiographical tradition.

Hu's concluding section 'The Martyr's Afterlives' on Qiu's legacy goes beyond the cultural implications of Qiu's martyrdom. This section guides readers through an examination of the 'material objects of Qiu Jin's commemoration - the tombs, shrines, and pavilions from 1911 to 1980s' (307). Hu challenges the ways (post-)socialist China appropriates Qiu's 
legacy for economic and political benefits. Under the leadership of the Chinese Communist Party, the interpretation of Qiu's sculpture at the West Lake in Hangzhou becomes an emblem to 'instill revolutionary spirit and patriotic sentiments' (331). At this point, Hu's biography of Qiu takes on a new meaning to criticise the political violence in post-socialist China. Although Qiu's tomb was at last built at the West Lake after 'seven more burials of her remains throughout the twentieth century' (7), the Party manipulates the interpretations of her legacy. Hu turns readers' attention to their own time 'when state-sponsored political persecutions had become so ordinary' for commemoration and contemplation (332). Hence, Hu's emblemisation of Qiu suggests that her tomb 'might be seen as a stand-in for all those tombs that were not built, all those deaths not identified and remembered, all those bodies that never found a final resting place' (332).

A major strength of Hu's prosopography is her eclectic and hybrid approach to life writing. She combines Sima Qian's approach to historiography, Virginia Woolf's conviction of recounting the lives of the obscure, Derrida's ideas of mourning in Work of Mourning, and the Chinese motif of zhiyin (soul mate) to recount the story of friendship between the three women. Readers interested in learning about the Chinese convention of life writing would find Hu's biography informative. In Chapter Four, 'The Arts of Mourning,' Hu intriguingly details Wu and Xu's 'seven biographical sketches of Qiu Jin' (187). The chapter is then divided into 'Biography,' 'Poetry,' and 'Burial,' exemplifying the 'full range of the Chinese subgenres of life writing' from the formal biography and the private biography, the memoir, to the sacrificial prayer and the epitaph (187).

$\mathrm{Wu}$ and $\mathrm{Xu}$ re-interpreted the assumptions of their chosen life-writing genres to commemorate Qiu. Through recording the obscure lives and the significance of $\mathrm{Wu}$ and $\mathrm{Xu}$, Hu Ying's study reveals an agenda to recuperate the hidden histories of unsung heroines in modern China. For instance, it is subversive for $\mathrm{Wu}$ as a woman to take up the role of a 
biographer. Also, Wu goes a step further to adopt the format of formal biography (189) to mourn Qiu in a time when Qiu was still a state criminal in 1908, the year she was decapitated. $\mathrm{Wu}$ and Xu's biographies and burial assume critical importance after Qiu's death because of the recuperation of Qiu's posthumous reputation and dignity. Hu clarifies at the outset of the book that Qiu's body did not receive an immediate burial because of the 'Qing legal code of lianzuo (punishing relatives of convicted criminals)' (1). This means $\mathrm{Wu}$ and $\mathrm{Xu}$ were the only ones who had the courage to mourn the persecution of Qiu publicly. They collected Qiu's body, which was randomly discarded by total strangers. Xu composed an elegy and Wu carved an epitaph to complete the building of a modest tomb at the side of West Lake in the same year of Qiu's death. In this way, the biographies and burial of $\mathrm{Wu}$ and $\mathrm{Xu}$ invoke public attention and sympathy to Qiu's death, perpetuate Qiu's legacy, and prevent her legacy from falling into obliteration.

Hu's prosopography offers a glimpse of the process of women's enlightenment during China's transition from the late-Qing era to the Republican period (1912-1948) through the life of Qiu Jin. Qiu's active participation in revolutionary activities signals 'the arrival of a new kind of woman' (122). This kind of woman has 'quite a bit of fun' (122) and freedom in comparison to their counterparts who live a sedentary, feeble, and domestic lifestyle. Apart from poems, epitaphs, and third-person testimonies, Hu effectively reads the images of Qiu in photographs from a gender perspective. For instance, the androgynous portrait of Qiu (121) shows her in a dark Western man's suit and 'leaning rakishly on a cane' (120) remotely echoing the sapphist self-fashioning seen on women writers such as Radclyffe Hall and Charlotte Mew in early 20th-century England. Qiu's cross-dressing, however, epitomises certain late-Qing intellectual women's rebellion against the physical and psychological bondage imposed on them on a daily basis such as foot-binding and arranged marriages. 
Another photograph of Qiu, perhaps at her most iconic, presents her in traditional Japanese attire in a 'voluminous kimono,' her hair dressed in a 'Nihon-gami style' (traditional Japanese hairstyle), and her left hand holding a dagger. Qiu's adaptation of 'the Chinese tradition of the swordsman,' the 'Japanese Bushido,' and 'Russian anarchism (indicated by the dagger)' (138) to her own swordswoman persona is telling of her own invention to inhabit a female body. By performing a sword dance and treating it as part of her persona, Qiu challenges her contemporary reformist Liang Qichao's 'convenient figure of the frail maiden' (143). Qiu's sobriquet name, 'Swordswoman of Mirror Lake,' complies with her self-fashioning in the photograph to embody a culture of xia (swords[wo]man) towards the end of the Qing dynasty (1636-1912). The sentiments to save the nation from Western imperial powers during this period were coupled with revolutionary activities against the Qing government. These socio-political crises propel the righteous ideal of xia to merge with the figure of female assassin.

Hu testifies to Elizabeth Gaskell's advice for an aspiring biographer: 'If you love your reader and want to be read, get anecdotes!' (Lee 59) She excels in adding anecdotes about Qiu to highlight the idiosyncrasies of her subject. For example, readers may find it striking to know that Cai Yuanpei (1868-1940), the Chinese educator and the president of the Peking University implemented an education of female assassins in the Patriotic Women's School as "“a kind of training school for future assassins," with a curriculum that featured stories from the French Revolution and Russian anarchism as well as chemistry classes that prepared students for bomb making.' (146). Another fascinating anecdote appears when Qiu was made to write a confession when she was captured. Qiu wrote her confession 'in a foreign language with a fountain pen' (179), manifesting her protest against the injustice imposed on her. The charge, as Hu finds, does not adhere to the Qing legal codes because no 'hard evidence indicating armed rebellion' existed (178). Hu's use of anecdotes, moreover, makes them 
function as foreshadowing devices of Qiu's death $(163,167)$. Such foreshadowing improves the structure and coherence of Qiu's brief life which ended at her 31st year.

Although Hu Ying writes a compelling narrative that is supported by careful research on Qiu and her two friends, she does not avoid occasional speculation in trying to provide a clearer picture of the intricate relations between different relatives and friends of her subjects to non-native Chinese readers. Life writing is a collective of fluid and hybrid subgenres, but any creativity devoted to weaving the fragmentary research materials together has to be bound by factual evidence. Hence, expressions indicating guesswork such as 'might have,' 'would have,' (70) 'perhaps,' (162, 166, 167, 177), 'speculations,' (162) and 'possible' (166) should be avoided.

Impersonating one of the subjects, $\mathrm{Wu}$, is also precarious. Readers may understand that $\mathrm{Hu}$ tries to emphasise the political contribution of $\mathrm{Wu}$ in Chinese-American relations in the early 20th century. Spelling out that $\mathrm{Wu}$ 'attempted to change the course of history' (259), however, is an overly ambitious claim. In mentioning the ease of reading, even as a native reader of the Chinese language, I appreciate Hu's provision of Chinese characters and a glossary of selected names at the end. I imagine, however, it would be more efficient for non-native Chinese readers if $\mathrm{Hu}$ could make the intricate relationships more visual. She could have inserted a family tree of the large families and the wide range of friends and official networks of the three subjects at the outset of the book to avoid readers needing to look up a name that had appeared somewhere previously - but where?

Hu's prosopography of Qiu Jin, Wu Zhiying, and Xu Zihua would be of interest to readers interested in modern Chinese history and literature, Republican Chinese women histories, and the convention of Chinese life writing. The book presents well-researched materials in a lively and lucid style, covering a wide range of topics from Buddhism, poetry, 
and calligraphy, to mythologies and an exegesis of the divination classic, the Book of Changes. Above all, the biography ends with a turn in the last chapter, relating Qiu Jin's legacy to the present. Mao Zedong's complaint about his visit at the West Lake 'surrounded by ghosts' and his order for 'thirty tombs to be demolished overnight' (325) took place only half a century ago. Hu's biography, ultimately, challenges the 'miscarriage of justice' (182) in modern China at large.

The support of $\mathrm{Wu}$ and $\mathrm{Xu}$ for Qiu Jin reminds readers of the potential of ordinary and private commitment to reach an emblematic significance of justice and subversion long after the burials took place.

\section{Reference}

Lee, Hermione. Biography: A Very Short Introduction. Oxford: Oxford University Press, 2009.

Jessica Siu-yin Yeung

SOAS University of London 